\title{
Reviving Parents' Life Momentum: A Qualitative Evaluation of a Parent Education Program Adopting an Existential Approach
}

\author{
Siu-Ming To ${ }^{*}, 1$, Siu-mee Iu Kan ${ }^{2}$, Kcon-wah Tsoi ${ }^{1}$ and Ting-sam Chan ${ }^{2}$ \\ ${ }^{I}$ Department of Social Work, The Chinese University of Hong Kong, Hong Kong \\ ${ }^{2}$ Hong Kong Institute of Educational Research, The Chinese University of Hong Kong, Hong Kong
}

\begin{abstract}
This paper reports the results of a qualitative analysis of the participants' perceptions and experiences of a parent education program adopting an existential approach. With a critical review of the changing social context of parenthood and the provision of parent education in Hong Kong, the paper discusses the theoretical underpinnings, key components, and the design of a growth- and meaning-oriented parent education program. This program comprised six 5hour sessions held weekly. The participants included 43 Hong Kong Chinese parents. An evaluation study was conducted to explore the outcomes of the program, which was composed of a non-equivalent comparison group design, a subjective outcome evaluation survey, and post-intervention focus group interviews. The current paper focuses on reporting the qualitative examination of the data collected through five post-intervention focus groups. Twenty-five participants were randomly selected and invited to join the groups. The recurrent themes extracted from their narratives reveal their perceptions of the impacts of the program on their enhancement of self-understanding and personal growth, integration of life through life review, reset of life priority, affirmation of the parent-child relational connection, changes in parent-child relationships and interactions, and cultivation of mutual support and mutual learning. Based on the qualitative findings, the paper explores the relevance and potentials of this approach in re-conceptualizing parent education in the Hong Kong Chinese context.
\end{abstract}

Keywords: Existential approach, meaning, parent education, parenthood, parenting.

\section{INTRODUCTION}

The current social concerns over parenting in Hong Kong have serious implications for rethinking the direction of parent education [1-4]. Under the present dominant ideology of parent education, people tend to focus on the predicaments surrounding families while neglecting the opportunities embedded in parenthood for enhancing life advancement, strengths and possibilities for parents to seek positive changes $[5,6]$. As such, a paradigm shift from a problem-focused parent education to a growth- and meaningoriented one has been prominent [4,7-11]. Based on the qualitative data of an evaluation study, this paper examines the parent participants' perceived outcomes and experiences of a parent education program adopting an existential approach. The program was composed of 30 hours of seminars and workshops. The participants included 43 Hong Kong Chinese parents. A mixed-methods approach to evaluation was used in this study, comprised of a nonequivalent comparison group design involving pre-test and post-test assessment data, a subjective outcome evaluation survey, and five post-intervention focus group interviews. The present article focuses on reporting the results of the qualitative examination of the data collected through the post-intervention focus group interviews, which contain

*Address correspondence to this author at the $4 / F$, T.C. Cheng Building, United College, The Chinese University of Hong Kong, Shatin, Hong Kong; Tel: (852) 3943 7375; Fax: (852) 2603 5018;

E-mail: smto@swk.cuhk.edu.hk participants' rich articulation of their perceived outcomes and experiences in the program.

\section{THE CHANGING SOCIAL CONTEXT OF PARENT- HOOD IN HONG KONG}

It is observed that life stresses and other social pressures usurp the time and psychological availability necessary for parenthood. In the past thirty years, families in Hong Kong have undergone a huge transformation. The study conducted by Chow and Lum [12] suggests that young couples tend to postpone childbirth, bear fewer children, and even choose to be childless. The average annual population growth rate over the past decade in Hong Kong was around $0.5 \%$, which was mainly attributable to the low fertility rate. Worries over long working hours and the escalating cost of childrearing are the major reasons that couples hesitate to become parents. According to a survey conducted by The Hong Kong Council of Social Service in 2006 [13], more than 200,000 families had one or both parents working up to 60 hours per week. Such long working hours may increase parental stress and affect family relationships and parent-child interactions [14]. There is also a prevalent view among people in Hong Kong that raising children is costly, and thus more couples opt to stay childless in order to enjoy a more comfortable life [12]. The discourse of globalization further drives Hong Kong parents to accept that possessing high competitive advantage is essential for their children to secure a prosperous future [15]. Parents tend to internalize the dominant ideology of accepting the responsibility to secure 
all developmental outcomes of their children [16]. As a result, parents' enjoyment and confidence in carrying out the parenting role are seriously sabotaged [4, 17-19].

\section{THE SIGNIFICANCE OF ADDRESSING PARENTS' EXISTENTIAL CONCERNS IN PARENT EDUCATION}

Helping stressed-out parents cope with parental stresses and childrearing challenges has been regarded as one of the major themes in parent education. A review of the development of parent education in Hong Kong reveals that parent education is commonly offered by parent education practitioners who impart parenting knowledge and skills to parents through various parent education programs, which aim to promote positive physical, intellectual, psychological, and social development of children $[1,20,21]$. Nevertheless, in their assessment of the existing mode of service provision, Chan [5], Lam [1], Lam and Kwong [2], Leung and Lam [3], and To and Chan [4] comment that parent education programs in Hong Kong are rather problem-focused. It is observed that parents are mainly helped to confront the problems of their children and themselves. As a result, the parents easily gain a message from these programs that they need to be taught different complex skills in parenting. The contribution of parents in childrearing seems to be undermined. In addition, the necessity of making sense of parents' lived experience is seldom treated as the central focus during the provision of parent education. This is a notable omission because the exploration of parental meaning and strengths can help construct parents' sense of self and their roles as parents, as well as reinforcing positive parenting practices [6].

Findings of accumulated research have demonstrated the importance of pursuit of meaning in life among human beings. For instance, it was found that presence of meaning was positively associated with positive personality traits [22, 23], satisfaction with self $[24,25]$, and satisfaction with life $[24,25]$. Applying these findings to parental meaning, findings of previous research have also pointed out the significance of addressing parents' pursuit of their life concerns in parent education programs [6, 7, 26]. Hills and Knowles [27] have adopted an experimental comparison group with longitudinal design for a program evaluation of parenting. They remarked that knowledge and skills in parenting would not be consolidated unless personal meaning is found and owned. Moreover, based on the findings of a phenomenological study, First and Way [28] further suggested that parenting wisdom will be amassed through transformative learning. The qualitative study conducted by Wolfe and Haddy [29] also found that parent education programs with emphasis on and recognition of parents' life experiences and generation of meaningful interactions with children can enhance parents' awareness, sense of empowerment, social support, and parenting competency. Furthermore, an outcome evaluation study of the Nobody's Perfect Parenting Programme, which emphasized the experiential knowledge generated by parents and the promotion of active group participation, indicated a significantly increased level of parenting resourcefulness, better parent-child interactions, and more effective child management [30].
Similar studies are also found among local parent education scholars. They assert that the need of the parents is beyond the knowledge and skills in childrearing [1, 3, 8, 21]. The large-scale mixed methods study conducted by Tam et al. [21] affirms that the significance of equipping parents with knowledge and skills should not rule out the importance of fostering parents' holistic development. Furthermore, as shown in the qualitative study of Lam [1], the most powerful source of influencing children in a positive direction is parents' willingness to share their own living examples of who they are. Leung and Lam [3] also regarded that knowledge and skills-based parent education programs fail to bring deep reflection and changes from the "inside out." Additionally, sometimes an enhanced self-perception of skills mastery on the side of the parents will increase their control over their children in an undesirable way. Subsequently, parent-child relationships may be worsened as an unintended result.

Moreover, under the influences of the traditional Chinese parenting concept of "guan," which emphasizes the role of parents in guiding and shaping the lives of their children and helping them succeed in lives, many Hong Kong parents hold themselves responsible for the developmental outcomes of their children, especially in the academic sphere $[15,31$, 32]. Emphasizing their roles in ensuring the life outcomes of children, these parents therefore attach much importance to their performance in childrearing. Yet, the unpredictability of children's developmental outcomes has turned parenting into an uncertain and risky endeavor, causing parents to do more and more in order to help their children succeed, which may lead to severe competition among parents and undue parental stress and anxiety [3].

In response to the current situation in which the joy and satisfaction of being parents is tremendously discounted in Hong Kong society, To and Chan [4] tried to advocate a parent education approach that is grounded in an existential understanding of the life concerns, needs, opportunities, and challenges faced by parents. In their article, they have examined the rationale behind an existential approach to parent education, the goals and principles of this approach, its strategies in provision, and its applicability in the Hong Kong Chinese cultural context. As they recommended, both quantitative and qualitative studies are needed to explore the change process and outcomes of this approach and the factors conducive to its success. In this regard, the present study is a first attempt to investigate the perceived outcomes and experiences of an existential approach to parent education.

\section{THE THEORETICAL UNDERPINNINGS AND KEY COMPONENTS OF AN EXISTENTIAL APPROACH TO PARENT EDUCATION}

An existential approach to parent education should be regarded as a broad orientation rather than a specific model, which involves various meaning-oriented practices and transformative learning methods [10, 11, 19]. This approached is called "existential" because it perceives being a parent as involving in a life project that provides lifechanging experiences for both parents and their children [7]. Essentially, it emphasizes the exploration of parental meaning and tries to work with the life process of awareness 
in order to bring parents the possibilities of a richer and more meaningful childrearing experience [4]. It also sees the realization of the potentials of parents to become selfactualizing and generative individuals [5, 7]. There are five key components of an existential approach to parent education.

First, an existential approach to parent education believes that good parenting starts with continuous self-exploration and self-enrichment of parents' personal lives. When parents review their personal lives and expand their self-awareness of different life aspects, they can gain a deeper understanding of their parental attitude and determine the direction of their own lives as well as ways to nurture their children. It also recognizes an induction effect of parental involvement [5]. It means that parents always have the possibility to reshape their parental attitude as they gain new insights about themselves and their children.

Second, it facilitates the examination of parents' personal values and beliefs in parenting. Through a process of critical self-reflection, they can develop new ways of thinking about their lives. A deeper understanding of the meaning of parenthood helps parents resist intruding opinions from other people and insensible social standards. Being free from the restraints of prevailing standards and norms, parents are encouraged to reflect on the extent of the dominant discourse on their perception towards themselves and their children. They will be able to adhere to their own values and convictions with congruence when these conceptual constraints are freed.

Third, it recognizes parents' deep relational connection with their children. It emphasizes the prime importance of an indispensible natural bonding between parents and their children. Through the reassurance of a sense of connectedness, their innate tendency of having unconditional love and concern over their children is unfolded, which far outweighs the heavy burden of childrearing.

Fourth, it helps parents understand how child nurturing can be exercised through an existential lens. Parents are reminded that every child is unique and that they should remain flexible in applying skills depending on their children's temperament, age, development, and the context. They are also encouraged to shift from their children's behavior to understanding their needs and identifying with their subjective world.

Fifth, it enables parents to care about their own families and the society [7]. Reaffirming their own strengths and resources, parents can establish intimate relationships with others, like their spouses and other family members. It encourages parents to go beyond their family life and develop their capacity for understanding the needs of other parents and children and contribute themselves for cultivating a constructive environment conducive to the well-being of parents and children.

An existential approach has been adopted in the arenas of education, counseling, and family therapy [10,11,33], but in the domain of parent education, related research activities are still scarce. It is thus worthwhile to conduct a study to fill the knowledge gap by examining the perceived outcomes and experiences of this approach to parent education.

\section{THE PROGRAM}

The parent education program was designed and conducted by one of the authors with the support of the members of the Hong Kong Parent Education Association (HKPEA). It is a non-profit making organization formed by a group of social workers and parent education practitioners in Hong Kong. All its members have rich knowledge, skills, and experience in providing parent education.

The program was consisted of three seminars and three workshops, which were held weekly. Each session lasted about five hours. The goals of the program involve: (1) helping parents gain a deeper understanding of the meaning of parenthood; (2) motivating them to experience parental growth so that they can treasure and appreciate their roles as parents; (3) reducing parental anxiety in meeting social expectations and standards in parenting; (4) developing a set of positive meanings as the foundation on which to build a constructive parent-child relationship; and (5) creating a mutually supportive environment for parents to have inspiring sharing. A pre-program interview was arranged to secure the participants' readiness for and commitment to the program.

In the first three sessions, the program placed a strong emphasis on clarifying and reflecting upon the meaning of parenthood. The participants were helped to examine how their worldviews, which were influenced by their own life experiences and the dominant ideology of parenting, affected their perceptions of themselves and their children. By scrutinizing the underlying assumptions of the ideology, the participants could re-grasp the core meaning of being a parent and engage in doing what is really worthwhile in parenting. The significance of reaffirming the deep parentchild relational connection and identifying with children's daily experiences was also highlighted. Based on a strengthened sense of parent-child relational connection, the participants could embrace and enjoy the challenges in parenting instead of fearing and avoiding them. The participants were also encouraged to recognize their own talents in parenting and to explore ways for personal growth and development.

In the consecutive three sessions, the participants were further divided into six groups, each consisting of seven to eight parents. The participants' background was considered in the division of groups such as gender, age, prior acquaintance, and age of children. Through the use of experiential exercises and life review activities, the participants were facilitated to reorganize their lived experience for the creation of coherence in life and ascertained future parenting directions [34]. The participants reflected on the significant life episodes and re-owned the memorable stories of their childhood, their family, and their parenthood, with which they could create new meanings in relation to the present self, discover an enlarged sense of possibility of being a parent, and commit to continuous growth in parenthood. A mutually supportive environment was also created to help the participants open their minds to listen to others' stories and give one another genuine feedback. A facilitator was assigned for each group to ensure that all participants understand and follow the instructions of the host facilitator. He/she also tried to bring the group back 
to track in case diversions were found. The host facilitator and the group facilitators were all members of the HKPEA.

\section{METHOD}

Post-intervention focus groups were taken as the qualitative evaluation method in this study. According to Shaw [35], the use of focus groups is one of the promising developments of qualitative and participatory evaluation. Compared with individual interviews, focus groups offer the evaluator the opportunity to study the ways in which individual participants collectively and interactively make sense of their experiences in the program and construct meanings of them.

\section{Participants}

A total of 43 participants joined the parent education program. They were openly recruited through one of the Federations of Parent-teacher Associations (FPTAs). In Hong Kong, FPTAs are formed to assist the establishment of parent-teacher associations (PTAs) in its district, enhance the coordination and communication of PTAs, and to promote parent education and deepen home-school cooperation [36]. All the Chinese parents had at least one child in kindergarten, elementary school, middle school, or high school. Table 1 shows the demographic characteristics of the participants. Twenty-five of the 43 participants were invited to join the five post-intervention focus groups. To ensure a mixed gender profile in each focus group, one male participant was invited to each group, while the females were selected by simple random sampling, thereby representing the views of different group experiences and avoiding uniformity of experiences. All participants have given written consent. The names of the participants have also been changed for the sake of confidentiality and protection of their identities.

\section{Data Collection}

Ethical approval for the study was granted by the Survey and Behavioural Research Ethics Committee, The Chinese University of Hong Kong. A total of five post-program focus groups were led by the researchers (the first three authors of this paper) who had not participated in the design and implementation of the program. Each focus group lasted for one-and-a-half hours. Some guiding questions targeting the participants' perceptions and experiences were set as the interview guide, and these questions were posed during the focus groups in a more open-ended manner. All focus groups were conducted in Cantonese, a dialect in China. The questions were centered on the exploration of participants' expectations, perceptions, impressive experiences, opinions towards the group atmosphere and interaction, inspirations towards parent education, and improvement of the program.

\section{Data Analysis}

The content of the tapes were fully transcribed after the focus groups. Three researchers (the first three authors of this paper who have not participated in the program) coded
Table 1. Demographic characteristics of participants $(n=43)$.

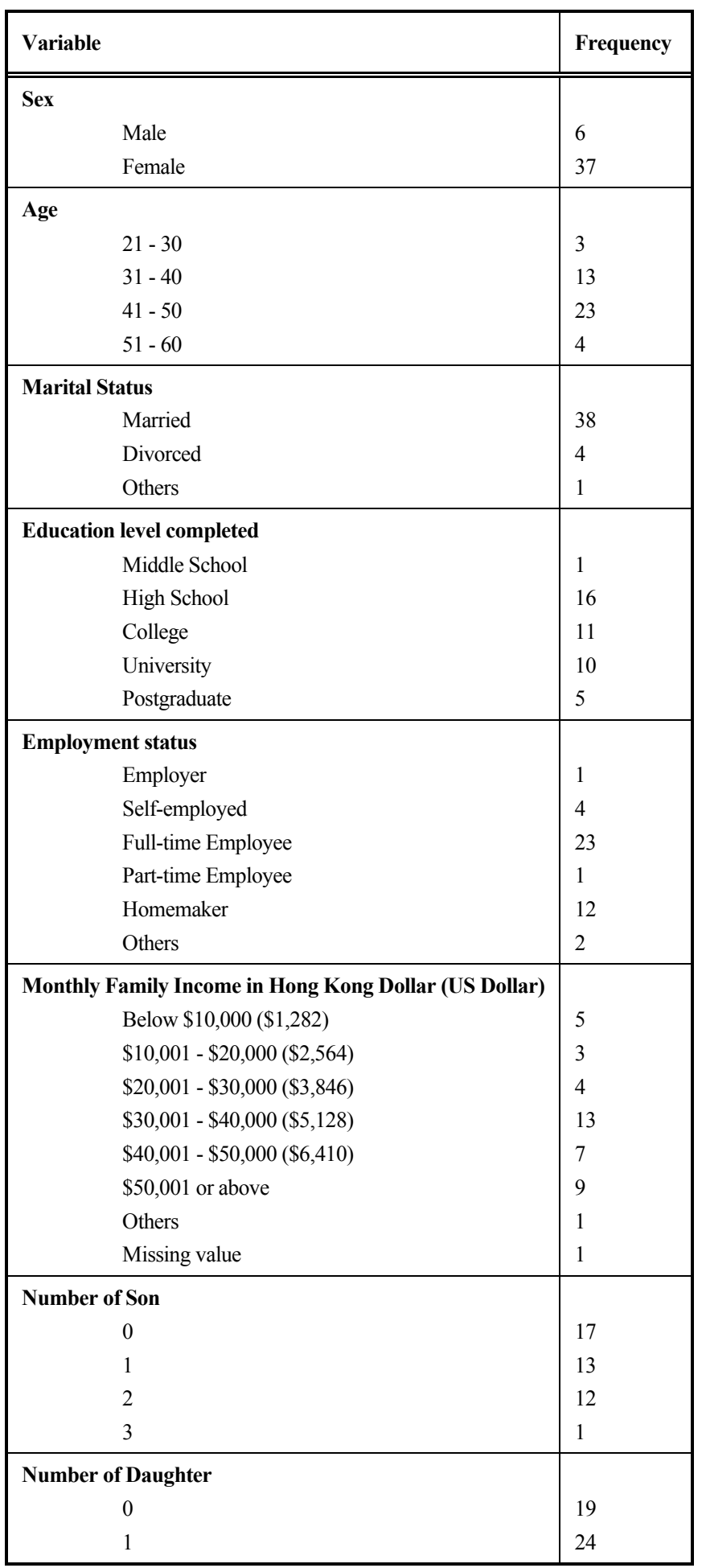

the data and identified significant themes across the entire data set [37]. The researchers first read and reread the transcripts to get a sense of the entire description narrated by all the participants. Their immediate impressions with regard to the participants' perceptions and experiences were made. They also took notes that reflected their initial thoughts and feelings. Then they read every line of the transcripts cautiously to search the "meaning units" [38]. They assigned codes to these meaning units and categorized the codes. 
At the next stage, the researchers identified and labeled the themes by comparing and categorizing the codes. Theme is regarded as the form capturing "something important about the data in relation to the research question, and represents some level of patterned response or meaning within the data set" [37, p.82]. The researchers listed the themes and made sense of the connections that were emerging between themes [37]. The connections between themes uncovered in the transcripts were examined. Finally, the major themes were summarized, together with quotations that best illustrated the themes.

The trustworthiness of this study was assured through the following two strategies [39]. First, a repeated crosschecking of the participants' perceptions and experiences was carried out. The selected themes were also discussed and validated. When a discrepancy arose between their understandings of the narratives, the researchers kept exchanging opinions until agreement was achieved [38]. Second, the researchers were conscious of the importance of the audit trail [38], thus all tape records, transcripts, process notes, and data analysis products were properly maintained.

\section{FINDINGS}

The following themes were identified from the participants' narrations of their experiences in the program. These themes unraveled and summarized in what ways the participants made sense of those experiences and fostered a new understanding of parenting and parent education.

\section{Enhancement of Self-Understanding and Self-Nurturing}

In consistent with the belief of an existential approach to parent education that parenting should start with parents' self-management and self-enrichment of their own lives, the opinion that the participants' self-understanding and selfnurturing were enhanced after the program was the first main theme to emerge in the focus group interviews. Motivated by the drive toward personal growth in parenthood, parents are also capable of enriching children's well-being. They can assume responsibility for their choices and decisions, and they can find effective ways to resolve problems and difficulties in parenting. Two participants obtained the following insights during the program:

"I think every person is the same, which means if you want to be a good parent, the first thing you have to do is to understand yourself, nurture yourself, and revitalize yourself, and in this way everyone can be a good parent." (Mother L)

"The practitioner stimulated my passion and revitalized my personal qualities in parenting. I think it is very important because only if you have the aspiration can you become more devoted and happier while interacting with your children." (Mother P)

Other participants also held that the practitioner brought about the essential ingredients of the growth momentum in parenthood, which include self-understanding and selfnurturing. As the participants highlighted, parents could hardly nurture their children and family without nurturing themselves first. It does not mean that parenting knowledge and skills are not important, but fostering parents' personal growth provides a solid foundation for knowledge and skills transfer.

\section{Integration of Life Through Life Review in the Program}

Every parent has a stock of stories depicting his/her life experience as a child, as an adult, and as a parent. By recollecting the participants' life stories, they can re-author their past experiences and reflect on their impacts on current parenting practice [5]. They can also discover their gains and accomplishments in being a parent [9]. Nearly all the participants recounted that narrating the significant episodes and events in their lives was beneficial to parent enhancement. Two participants said:

"The program gave me an opportunity of selfevaluation, and I could reorganize my life experiences, no matter positive or negative. It is good for me because all these experiences have exerted effects on my life attitude. After the reorganization of my life experiences, I found that life should be very simple in the way that we should cherish our children." (Mother Q)

"It is rare for me to review my childhood, my family and my own development. But when I started doing this, I found that it is beneficial to my parenthood and my childrearing." (Father I)

Their narratives illustrate that the formation of a parent's present identity is not built upon a systematic body of knowledge of parenting but the integration of a parent's lived experience. Telling and interpreting their own stories, participants can reorganize their lived experience for the creation of coherence in life and reconsider the direction of childrearing.

\section{Reset of Life Priority}

Alongside the perceived outcome of life integration through life review is the theme of reset of life priority. In the program, there were exercises that were oriented to the setting of present life priority in the program. For instance, the participants were asked to write a letter to their beloved before death. Many participants pointed out that this exercise could help them gain a new outlook in what was truly important in their lives and as a result could ascertain their future direction in parenting. Below are two of their genuine comments shared:

"I have had serious struggles in recent years whether I should spend more time on work or on family. I have considered and reconsidered which way I should walk along to. At last I chose a stable job and spent more time on my family. In fact, I was a little bit unsatisfied. But after the program, I knew that I had made a right decision." (Mother $\mathrm{R}$ )

"In the past I kept working after I returned home, but now I learn to put aside my work 
and play with my son. In fact, what he longs for is that I can play with him. It is my son who helps me rethink my life priority." (Father W)

An existential approach to parent education encourages parents to live in accordance with their own directions and ideals of life. This kind of pursuing authenticity is one of the important goals of existential work that motivates parents to express and actualize their views of themselves and their families. They can choose to rearrange their lifestyles to be consistent with their life priority. When parents find what matters to them most, they will become more energetic and devoted to their parenthood.

\section{Affirmation of the Parent-Child Relational Connection}

As shown in the findings, what supports the participants to face the challenges in parenting is a strengthened sense of parent-child relational connection. The participants found that because the parent-child connection was irrevocable, they were willing to contribute a great deal both physically and psychologically to take care of their children. The element of unconditional love in parenting was based not on mere responsibility but was derived from an innate tendency to love and care for their children unconditionally. Two participants narrated their reflections:

"I came home and looked at my daughter she is really my 'flesh and bone.' The practitioner encouraged us to review the photos that were taken when my child was born. At that time I often asked myself how I could take care of my baby. Now I am amazed by my ability to bring her up." (Mother R)

"With a flash of insight I realized that my child is my "flesh and bone" and my love for my child is really unconditional. Such an insight helps me enjoy my parenthood and consider how to rear my child." (Mother U)

The use of "flesh and bones" to describe the inborn generative relationship between parent and child was prevalent in Chinese culture. It believes that the parent-child connection is deeper and longer lasting than any other human relationships. The care provided by parents for their children is thus irreplaceable. Moreover, through caring for children, parents' lives are enriched with meaning. Their sense of contentment in parenthood and perceived capability in parenting were also enhanced.

\section{Provision of the Space and Freedom for Children to Grow}

The phenomenon of over-protective parenting has aroused public concern in recent years [16]. Parents often transmit their stresses and anxieties arising from their own life concerns and challenges to the daily lives of their children, worrying that they cannot provide enough care and support for their children and expose their children to risks [3]. The program strived to enhance participants' potential to scrutinize the dominant discourses in child development and construct alternative discourses. The following narratives can represent the views of other participants:
"The program reminded me to think about whether our children need so much protection. I enjoyed freedom when I grew up and I was fine! Do children need so much protection?" (Mother B)

"I could manage my own life when I grew up. Why can't my child? Now I always remind myself that I should allow more space and freedom for him to grow. I feel more relaxed now. I try my best to help my child but I resist putting so much pressure on myself. It seems that everything becomes smoother!" (Mother L)

Inspired by the messages of the program, they asserted the individuality and self-actualizing tendency of their children. They understood that children needed opportunities, and they could not push their children to walk along the life path under their shadow. They found that freedom should be allowed for their children to grow. When they recognized this, their parental anxieties and feelings of guilt were reduced subsequently.

\section{Perceived Changes in Parent-Child Relationships and Interactions}

Nearly all participants reported that they examined their current parent-child relationships and interaction patterns more closely after the program. They validated the importance of good modeling and identification with their children's subjective world. They also learnt the art of listening to their children and became more sensitive in their use of compliment in parenting. Some participants narrated:

"The greatest impact of the program is that when I feel angry, I will try to consider her [the child's] perspective. I will think again about how I can teach her. I believe that I've found a correct way [in parenting], and it [the program] encourages me to walk along this way." (Mother E)

"I discuss [decisions] with them. Sometimes I share my own feelings with them. I also give them more recognition. In the past, even when they did something good, I seldom expressed my compliments to them." (Father F)

In the program, emphasis was placed more on reflection than skills training. It is believed that when parents regain momentum in being a parent, they will attempt constructive ways of interacting with their children. Furthermore, when parents have experiences of being understood, accepted, and recognized in the program, they will learn how to understand, accept, and recognize their children. This can explain why there were positive changes in parent-child interactions even though parenting skills have not been taught explicitly.

\section{Cultivation of Mutual Support and Mutual Learning Through Positive Group Experience}

Many parents find themselves quite isolated in childrearing. What they need is not only to acknowledge and 
reflect on what has happened to them, but also to find some persons to listen to, understand, and support them. Parent education in groups has been an effective method for providing mutual aid among parents [29, 40]. The support from other parents can allow them to instil hope and encourage them not to give up while feeling powerless. The following quotations indicate the participants' awareness of the positive effect of mutual support:

“Through listening to other group members' sharing, I understood that every person has her own story. I was not the only one who suffered! I could air my grievances and feel better." (Mother C)

"In the program we met some group members who faced similar problems just like me, and at that moment, I found that my problem was not so serious." (Mother V)

Besides mutual support, mutual learning is another type of experience that is essential to mutual aid [19, 41]. Parents can learn from each other to cope with their problems. Since the participants share common life concerns, they are receptive to other group members' feedback and suggestions. They can also rediscover within themselves the enormous potentials for overcoming the challenges. Some participants recounted their positive experiences in mutual learning:

"Every group member puts much effort and tries her best in childrearing. Each person has her own character and parenting style. Through the sharing I could find the strengths of each person." (Mother A)

"When I listened to other group members' sharing, I could learn about how other parents coped with the problems in childrearing. I could take their experience and wisdom as my reference. Moreover, through the sharing of male group members, I could have a deeper understanding of males' perceptions and viewpoints. Therefore, I knew how to put myself in my family members' shoes." (Mother C)

\section{Areas for Further Improvement}

In spite of the positive feedback from the participants, they had identified two areas for further improvement of the program. First, some participants pointed out that readiness was prerequisite for a deep level of reflection and sharing. It is because they needed time to gain trust and establish rapport with other participants so that they could open their hearts to share their life stories and listen to others' feedback. Even though they were given adequate preparation in the pre-program interview, they still faced the struggle of disclosing their private and familial issues in front of other people. They contended that the group facilitators contributed significantly to enhancing their readiness because they modeled empathy, respect, and unconditional positive regard in the group process. Despite that, more information on the program design and content should be given beforehand so that they could be more prepared.
Second, many participants requested an increase in the number of program sessions and the provision of follow-up sessions. In their view, more time and guidance were needed to recount details of their life stories and reorganize their lived experiences in a coherent manner. Some of them narrated:

"I don't think I had enough time to review and reorganize all of my life stories. There were indeed some significant life issues that I had not touched on in the program." (Mother C)

"Sufficient time is required to review and reconstruct the meanings of our life stories. This is necessary for developing a deeper understanding of ourselves." (Mother G)

In sum, the program helped the participants reflect on the meaning, life experiences, and future direction of parenthood. They appreciated that much emphasis has been placed on channeling the respect toward parents' own life concerns. Positive influences have been exerted on the participants in non-manipulative ways. Their active participation in the experiential exercises and life review activities were also found. They also stipulated the need for publicity, continuity, consolidation, and development of such an alternative approach to parent education.

\section{DISCUSSION AND IMPLICATIONS FOR PARENT EDUCATION}

The findings of this study demonstrate that after joining the program, the participants became aware of the existential dimensions of being a parent. They understood the significance of creating meaning in their parental lives, acting in caring and enriching ways in parent-child relationships, and reaffirming the need to grow as a person and a parent. These findings illustrate how existentialism provides a new frame of reference in which to conduct parent education and explore new practice directions.

\section{Parent Enhancement in Parent Education}

Existing parent education programs seldom emphasize the growth momentum embedded in parenthood and the developmental effects of being parents [1,5]. Worse still, when they strive for equipping parents with knowledge and skills for dealing with the wearisome duties of childrearing and tackling children's misbehavior, they unintentionally amplify parents' sense of inadequacy and strengthen the belief that they have to meet uncountable challenges in the foreseeable future [2]. As a result, the gain and blessing of parenthood has been continuously underrated or even neglected [5, 7, 37]. The core message of an existential approach to parent education conveys that parenthood can stimulate the growth momentum throughout the rest of a person's life [4]. As reported by the participants of this study, they could hold a positive attitude towards parenting after the program. They felt content with their parenting role and enjoyed taking care of their offspring. Their confidence in childrearing has also been enhanced. The program helped them reposition parent education within the aim of enhancing parents' personal growth and self-enhancement, which involve developing self-awareness and sensitivity 
towards the self and others, appreciating and utilizing the opportunity for life advancement, and building trustful parent-child relationships. Their narratives remind our profession to facilitate parents to develop a more positive view on parenthood and encourage parents to make use of their competencies to achieve self-transformation [30].

\section{Experiential Knowledge Generated by Experiencing Parenthood}

Knowledge given by parenting experts cannot replace knowledge generated by experiencing parenthood [2, 41]. Parenting practice may be influenced by parents' knowledge and skills, but it also relies on how they interpret their lived experience in carrying out the parenting role. For the participants of this study, their devotion to parenthood and self-change in parenting are incurred by their conscientious review of and reflection on their lived experience. Consistent with the findings of Chislett and Kennett [30] and Leung and Lam [3], the experiential knowledge gained from embracing parents' personal life experience is more influential than knowledge transferred by parent education experts. In fact, the participants agreed that the contemplation on their own life events by itself could effectively induce them to acquire the necessary parenting knowledge and skills. Their experience echoes that review and reflection are the central part of the helping process in meaning-oriented practice [9, 11]. Parents can gain a wider, richer, and deeper discovery of the meanings of their parenthood and even foster new meanings of it [9]. It is contended that in parent education programs, participants should be facilitated to reorganize their biographical narratives and recognize the experiential knowledge accumulated by their personal experience [34].

\section{Transformation of Mutual Support Groups to Self-Help Groups}

Besides initiating changes in personal and family dimensions, the findings indicated that the participants could clearly pinpoint the value and significance of mutual support and mutual learning. Based on a group atmosphere of trust and respect, the participants were willing and ready to share with other parents. Their narratives fully illustrate the positive effect of mutual understanding and positive regard [40]. In fact, for the parents who are interested in forming self-help groups, they can be involved and trained to be group leaders and facilitators [42]. Through self-help groups, they can enhance parents' awareness of how they are subject to the influence of the dominant parent education discourses. They can expand their horizons through dialogical interaction, which means they can use their own reflexive selves to influence other parents' meaning-making process. In this way parents are co-constructing their stories and their identities [2]. Parents of these self-help groups can serve as supporters of other parents by establishing community-based parent support networks [42].

\section{Relevance of this Approach to the Chinese Cultural Context}

Hong Kong is a cosmopolitan city of both Chinese and Western cultures. The influence of Chinese culture on Hong Kong Chinese parents is salient. Harter [43] points out that while the western conception of self emphasizes the autonomous pursuit of personal goals and selfdifferentiation, the Chinese conception of self highlights the fulfilment of social roles and the achievement of social harmony. In Confucianism, family is regarded as the essential and most desirable environment for selfdevelopment. Only through continuous self-development can one's family be managed; as a result, family harmony can be achieved $[4,44]$. In this research, many parents perceived the major goal of parent education as allowing chances for parents to enrich their parenthood and personal enhancement so that they can set a good example for their children to follow, which are consistent with the findings of previous studies [3, 8]. With enriched self-development, the children will be positively influenced. They will learn to become a person with good self-regulation ability, strong moral character, and proper social conduct [26]. From an existential point of view, parents' transformative experience in parenthood has an enormous impact on their children's moral and spiritual growth [7]. The existential view on parent education can thus be said as relevant to the Chinese culture context [4].

\section{FUTURE RESEARCH DIRECTIONS}

As this qualitative research is a pioneering attempt to examine the applicability of an existential approach to parent education, there are several limitations that should be taken into account. These unanswered questions may be valuable for further examination in the future. First, due to its nature of naturalistic inquiry [39], the causality of the program effects on the participants' changes can hardly be verified. Moreover, the participants might have reflected on their lived experience of being a parent and wished to seek reinforcement for what they already thought. Since they had already contemplated the meaning of parenthood, it was easier for them to have positive experiences in the program. The applicability of meaning-oriented parent education to parents with different expectations, especially those who want a manual of parenting can be further explored [4]. Furthermore, although the findings provide evidence that support the need to increase the number of program sessions and the provision of follow-up sessions, the expansion of the current program design should be under thorough consideration because parents often prefer concentrated programs with a shorter duration of time [20].

Despite these unanswered questions, the present study makes several important contributions. It offers a knowledge base for understanding the significant aspects of an existential approach to parent education. It provides relevant reference materials for social workers and parent education practitioners to apply this approach in practice. It also stimulates other intellectuals to explore future directions of parent education.

\section{CONFLICT OF INTEREST}

The authors confirm that this article content has no conflict of interest.

\section{ACKNOWLEDGEMENTS}

Declared none. 


\section{REFERENCES}

[1] Lam CM. Parent education: revision and vision. Asian J Couns 2003; 110(2):147-68.

[2] Lam CM, Kwong WM. The paradox of empowerment in parent education: A reflexive examination of parents' pedagogical expectations in an action research project. Fam Relat 2012; 61(1):65-74.

[3] Leung TTF, Lam CM. The warrants of parenting: emotionality and reflexivity in economically disadvantaged families. J Soc Work Pract 2009; 23(3):353-67.

[4] To SM, Chan TS. Searching for the meaning of parenthood: an existential approach to parent education in the Hong Kong-Chinese context. Int Soc Work 2013; 56(4):467-81.

[5] Chan TS. A narrative analysis of men's interpretation of their fathering experience. PhD thesis. Hong Kong: The Chinese University of Hong Kong 2000.

[6] Walsh F. Family resilience: a framework for clinical practice. Fam Process 2003; 42:1-18.

[7] Hannush MJ. Becoming good parents: an existential journey. Albany: State University of New York Press 2002.

[8] Lam CM. In search of the meaning of parent education in the Hong Kong-Chinese context. In: Kane MJ, Ed. Contemporary issues in parenting. New York: Nova Science 2005; pp. 111-24.

[9] Lantz J. Meaning-centred marital and family therapy: learning to bear the beams of love. Springfield, Illinois: Charles C Thomas 2000.

[10] Lantz J. Worldview concepts in existential family therapy. Contemp Fam Ther 2004; 26(2):165-78.

[11] Wong PTP. From logotherapy to meaning-centred counseling and therapy. In: Wong PTP, Ed. The human quest for meaning: theories, research, and applications. $2^{\text {nd }}$ ed. New York: Routledge 2012; pp. 619-48.

[12] Chow N, Lum T. Trends in family attitudes and values in Hong Kong: final report. Hong Kong: The University of Hong Kong 2008 .

[13] The Hong Kong Council of Social Service. An overview of family services in Hong Kong. 2012 [cited 2013 May 30]. Available from: http://www.hkcss.org.hk/uploadfileMgnt/0_20132 2611328.pdf

[14] Ma JLC, Wong TKY, Lau LK, Pun SH. Perceived family functioning and family resources of Hong Kong families: implications for social work practice. J Fam Soc Work 2009; 12: 244-63.

[15] Waters JL. Geographies of cultural capital: education, international migration and family strategies between Hong Kong and Canada. Trans 2006; 31:179-92.

[16] Lui TL. Who says parents must be good persons? (in Chinese). Hong Kong: Step Forward Multi Media 2002.

[17] Kwok S, Wong D. Mental health of parents with young children in Hong Kong: the roles of parenting stress and parenting selfefficacy. Child Fam Soc Work 2000; 5:57-65.

[18] Leung C, Leung S, Chan R, Tso K, Ip F. Child behavior and parenting stress in Hong Kong families. Hong Kong Med J 2005; 11(5):373-80.

[19] To SM, Iu Kan SM, Tsoi KW, Chan TS. A qualitative analysis of parents' perceived outcomes and experiences in a parent education program adopting a transformative approach. J Soc Work Pract 2013; 27(1):79-94.

[20] Cheung SK. Parent education programmes in Hong Kong: are they effective? Hong Kong J Soc Work 2001; 35(1\&2):85-96.

[21] Tam WM, Lam CM, Cheng HM, Ho SC, Ma LC. The promotion of parent education in Hong Kong: a consultancy study final report. Hong Kong: The Chinese University of Hong Kong 2001.
[22] Mascaro N, Rosen DH. Existential meaning's role in the enhancement of hope and prevention of depressive symptoms. J Pers 2005; 73(4):985-1013.

[23] Schnell T, Becker P. Personality and meaning in life. Pers Individ Dif 2006; 41:117-29.

[24] Shek DTL. Life meaning and purpose in life among Chinese adolescents: what can we learn from Chinese studies in Hong Kong? In: Wong PTP, Ed. The human quest for meaning: theories, research, and applications. New York: Routledge 2012; pp. 335-55.

[25] Steger MF, Kashdan TB, Sullivan BA, Lorentz D. Understanding the search for meaning in life: personality, cognitive style, and the dynamic between seeking and experiencing meaning. J Pers 2008; 76(2):199-228.

[26] To SM. Development and validation of a quantitative measure for Chinese Sources of Parental Meaning. J Child Fam Stud 2015 Mar; p. 15 [cited 2015 Mar 19]. Available from: http://link.sp ringe r.com/article/10.1007/s10826-015-0168-9

[27] Hills MD, Knowles DW. Providing for personal meaning in parent education programmes. Fam Relat 1987; 36(2):158-162.

[28] First JA, Way WL. Parent education outcomes: insights into transformative learning. Fam Relat 1995; 44:104-9.

[29] Wolfe RB, Haddy L. A qualitative examination of parents' experiences in parent education groups. Early Child Dev Care 2001; 167:77-87.

[30] Chislett G, Kennett DJ. The effects of the Nobody's Perfect program on parenting resourcefulness and competency. J Child Fam Stud 2007; 16: 473-82.

[31] Chan SM, Bowes J, Wyver S. Chinese parenting in Hong Kong: links among goals, beliefs and styles. Early Child Dev Care 2009; 179(7):849-62.

[32] Cheung CS, McBride-Chang C. Relations of perceived maternal parenting style, practices, and learning motivation to academic competence in Chinese children. Merrill-Palmer Q 2008; 54(1):122.

[33] Walters DA. Existential being as transformative learning. Pastor Care Educ 2008; 26(2):111-118.

[34] To SM, So YY, Chan TS. An exploratory study on the effectiveness and experience of a parent enhancement group adopting a narrative approach. J Soc Work 2014; 14(1): 41-61.

[35] Shaw IF. Qualitative evaluation. London: Sage 1999.

[36] Committee on Home-School Cooperation. Introduction to federation of parent-teacher associations 2012 [cited 2012 May 30]. Available from: http://www.chsc.hk/section2_2.php?lang_id=1

[37] Braun V, Clarke V. Using thematic analysis in psychology. Qual Res Psychol 2006; 3:77-101.

[38] Padgett DK. Qualitative methods in social work research. $2^{\text {nd }}$ ed. Thousand Oaks: Sage 2008.

[39] Lincoln YS, Guba EG. Naturalistic inquiry. Newbury Park: Sage 1985.

[40] Solomon M, Pistrang N, Barker C. The benefits of mutual support groups for parents of children with disabilities. Am J Community Psychol 2001; 29(1):113-32.

[41] Borkman T. Experiential knowledge: a new concept for the analysis of self-help groups. Soc Serv Rev 1976; 50(3):445-56.

[42] Webster-Stratton C. From parent training to community building. Fam Soc 1997; 78:156-71.

[43] Harter S. The construction of the self: developmental and sociocultural foundation. $2^{\text {nd }}$ ed. New York: Guiford 2012.

[44] Hwang KK. The deep structure of Confucianism: a social psychological approach. Asian Philos 2001; 11(3):179-204. 